\title{
Observatorio Inmobiliario
}

\section{CIUDAD Y TERRITORIO}

\section{ESTUDIOS TERRITORIALES}

ISSN(P): 1133-4762; ISSN(E): 2659-3254

Vol. LII, № 206, invierno 2020

Págs. 931-944

https://doi.org/10.37230/CyTET.2020.206.14

CC BY-NC 4.0

(c)

\section{El mercado de vivienda acusó la pandemia en el primer semestre}

\section{Julio Rodríguez-López}

Vocal del Consejo Superior de Estadística del INE.

\begin{abstract}
"Esta vez fue diferente. Por primera vez en 50 años, el mercado de vivienda del Reino Unido no fue responsable de la recesión. No se ha tratado de un pinchazo de burbuja como en 1989 y en $2007 . .$. Debe de recordarse que los precios de las viviendas dependen de las ventas que realmente suceden. La imposibilidad de comprar de cualquiera no afecta a la estadística de precios. Por desgracia, las consecuencias de la pandemia las sufren los jóvenes y los hogares de bajos ingresos. La restricción crediticia que reduce los préstamos hipotecarios a los compradores por primera vez está también ampliando la división económica. El que muchas personas queden fuera del mercado no tendrá impacto sobre los precios de venta"
\end{abstract}

Neal Hudson, 2020, "High house prices paint a partial picture of UK real estate", Financial Times, 6 de septiembre.

\section{Introducción}

- I comportamiento del mercado de vivienda - en el primer semestre de 2020 ha estado estrechamente ligado a las consecuencias de las medidas adoptadas para hacer frente a la pandemia de Covid 19. Las ventas de viviendas descendieron con intensidad en los meses de marzo y abril sobre los niveles precedentes. La posterior recuperación de las ventas desde junio no ha permitido alcanzar los niveles previos a la crisis, los de febrero de 2020.La evolución de las ventas parece haber afectado más a los precios de las viviendas y a la nueva construcción que a los alquileres.

En el presente trabajo se analizan en los dos primeros apartados la evolución de la economía mundial y de España, respectivamente. En el apartado tercero se describe la evolución de los precios de las viviendas en la primera mitad de 2020. En el cuarto apartado se resume la evolución de la demanda de viviendas, en la que ha ejercido una influencia negativa el comportamiento del empleo y de los salarios derivado de la pandemia. En el apartado quinto se comenta la marcha de la nueva construcción de viviendas y la evolución del stock de viviendas de nueva construcción no vendidas. En el sexto apartado se resumen los indicadores ligados a la construcción y venta de viviendas protegidas y las principales medidas legales adoptadas para apoyar a compradores de viviendas y arrendatarios afectados por la presencia del Covid 19. 


\section{El Covid-19 y el hundimiento de la economía mundial}

La pandemia del coronavirus Covid-19 ha inducido una penosa recesión en la economía mundial en el primer semestre de 2020 , en especial en el segundo trimestre del año. Destaca sobre todo la extensión que dicha evolución ha presentado, al afectar a un amplio número de países, con lo que se ha aproximado en extensión y en intensidad a lo que fue la gran depresión de los años treinta del pasado siglo.

Las políticas monetaria y fiscal desarrolladas han mitigado el retroceso registrado en la actividad y en el empleo, pero no han logrado compensar las pérdidas registradas por dichas magnitudes, que pueden terminar el año por debajo de los niveles existentes al inicio de 2020. Se ha advertido una reactivación en los primeros meses del tercer trimestre del año, pero no se puede considerar que dicha evolución sea una recuperación.

Las exportaciones no han alcanzado un crecimiento significativo, a la vista del descenso del comercio mundial. Ello ha afectado seriamente a la baja al turismo y a los viajes realizados. El desempleo ha afectado sobre todo a los ocupados con empleos menos estables y va a perjudicar seriamente a los aspirantes a entrar en el mercado de trabajo. La desigualdad ha sido otro rasgo de la recesión, puesto que no ha afectado por igual a todos los trabajadores ni a los distintos países, perjudicando sobre todo a los hogares con menores niveles de ingresos (CARmen \& Vincent Reinhart, 2020).

Los estímulos fiscales han tenido menos alcance que lo que parecian señalar las apariencias. Sí que ha funcionado una política monetaria muy expansiva, en la que los bancos centrales han bajado los tipos de interés, han aportado liquidez a la economía y han adquirido activos de los sectores no financieros. Los déficits públicos y los aumentos de la deuda han superado ampliamente las previsiones.

El agravamiento de la situación ha hecho crecer el nacionalismo populista y ha crecido la desconfianza entre la población. Se hace necesario desarrollar políticas que no empeoren los desequilibrios y también es preciso un manejo prudente de las políticas monetaria y fiscal. El retroceso del PIB ha sido más acusado en la Unión Europea que en Estados Unidos, posiblemente por el mayor alcance de los estímulos fiscales introducidos en este país (FIG. 1).

Estados Unidos va a desarrollar una política monetaria muy expansiva hasta 2023 , llevando los tipos de interés a los mínimos posibles. Desde la Reserva Federal se han pedido más estímulos fiscales al gobierno. El descenso del PIB de Estados Unidos en 2020 será del 3,7\% en 2020 ,

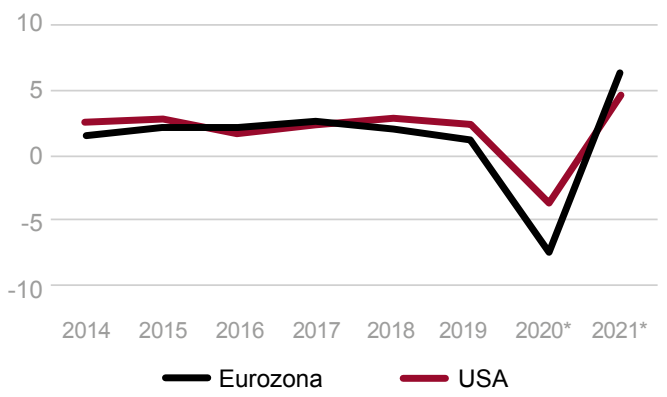

FIG. 1/ PIB, precios constantes. Tasas anuales de crecimiento, 2014-2021 (previsión). Estados Unidos y Eurozona.

Fuente: FMI.

descenso bastante menos acusado que el de la previsión inicial, que fue el 6,5\% (FINANCIAL TIMES, 2020).

Dentro de la Unión Europea los datos confirmaron las estimaciones iniciales acerca de un impacto económico considerable, descendiendo el PIB en un $3,6 \%$ en el primer trimestre y previéndose un descenso del $13,5 \%$ en el segundo trimestre. La explicación del amplio descenso del segundo trimestre descansó en la presencia de un periodo de confinamiento más prolongado que en el primer trimestre, con diferencias pronunciadas entre los estados miembros.

En mayo y junio la economía de la UE inició un proceso de recuperación que anticipó una recuperación más intensa en el tercer trimestre del año. El riesgo mayor de dicha previsión es que en la segunda parte del año tenga lugar una "segunda ola" de la pandemia, Ello generaría mayores destrucciones del empleo y un número mayor de insolvencias empresariales, lo que frenaría la recuperación.

\section{La economía española acusó el impacto de la pandemia}

La economía española sufrió plenamente las consecuencias de la pandemia de Covid-19 en el primer semestre de 2020, en especial en el segundo trimestre del año. Aunque aparecieron indicios de recuperación en los meses de mayo y de junio, esta evolución resultó frenada en los meses de verano del tercer trimestre.

La intensidad de la crisis puede superar los niveles de la de 2008-09 por el carácter generalizado de la misma entre las diferentes economías nacionales. El alcance de la crisis de 2008-09 se limitó a once países con economías avanzadas, mientras que en 2020 el carácter generalizado de la recesión permite calificar a la situación planteada como una nueva depresión. 
El confinamiento forzoso a que se sometió a la población española entre marzo y mayo de 2020 fue la causa de la fuerte caída de la actividad en el segundo trimestre de 2020. Frente a un descenso del PIB en el primer trimestre del 5,2\%, en el segundo trimestre el retroceso se elevó hasta el $18,5 \%$. La inversión en capital fijo fue el componente de la demanda interna que experimentó los descensos intertrimestrales más acusados, tanto en la construcción (-25\%) como en la inversión en bienes de equipo $(-27,8 \%)$.

Dentro de la Unión Europea, España fue el país que registró el mayor descenso del PIB en el segundo trimestre de 2020 , el $-18,5 \%$ frente al $-11,8 \%$ de la Eurozona, según Eurostat. La explicación de este intenso retroceso de la actividad se debió al importante peso del turismo y de los servicios en el PIB de la economía española. Las exportaciones retrocedieron de forma acusada $(-33,5 \%)$ en el segundo trimestre, resultando algo inferior el descenso de las importaciones $(-28,8 \%)$.

El Banco de España ha establecido dos escenarios respecto de la evolución de la economía en el tercer trimestre de 2020. Resulta evidente que, en este periodo, una vez terminado el confinamiento obligatorio de la población, la economía va a crecer. La intensidad del crecimiento dependerá de la mayor o menor fuerza con la que se haya producido el segundo rebrote de la pandemia, que en septiembre ha sido importante en algunas comunidades autónomas (BANCO DE ESPAÑA, 2020).

La recuperación del PIB en el escenario más favorable seria el $16,6 \%$ durante el tercer trimestre, mientras que dicha evolución resultaría menos expansiva en el caso de que los rebrotes de la pandemia alcanzasen una mayor intensidad (13\%). En el primer escenario la caída del PIB en 2020 sería del 10,5\%, mientras que en el segundo escenario el retroceso alcanzaría al $12,6 \%$.

La previsión de consenso establecida por Funcas seria de un descenso del PIB del $12 \%$ en 2020, frente a una cada sensiblemente inferior en la Eurozona, el 7,7\% (FIG. 2). La formación bruta de capital fijo $(-17,9 \%)$ y las exportaciones $(-21,5 \%)$ serían los componentes de la demanda que acusarían más las consecuencias del confinamiento provocado por la pandemia (FIG. 3). En 2021 el PIB de España podría crecer en un $7,3 \%$, mientras que el crecimiento de la Eurozona ascendería al $6,2 \%$.

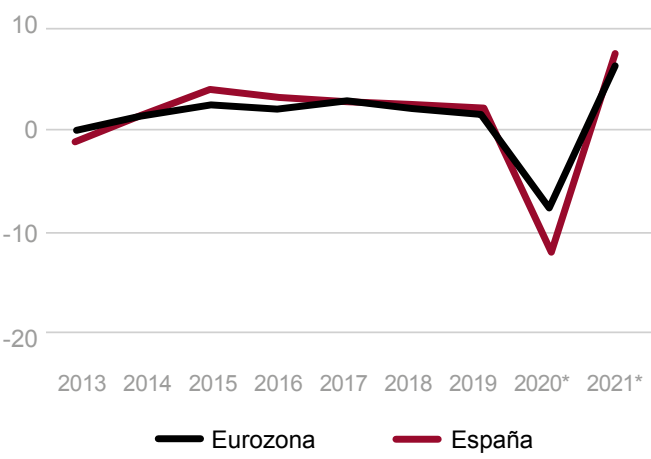

FIG. 2/ España y Eurozona. Tasas de crecimiento anual del PIB, precios constantes, 2013-2021 (previsión).

Fuente: INE, FUNCAS y BANCO DE EsPaña.

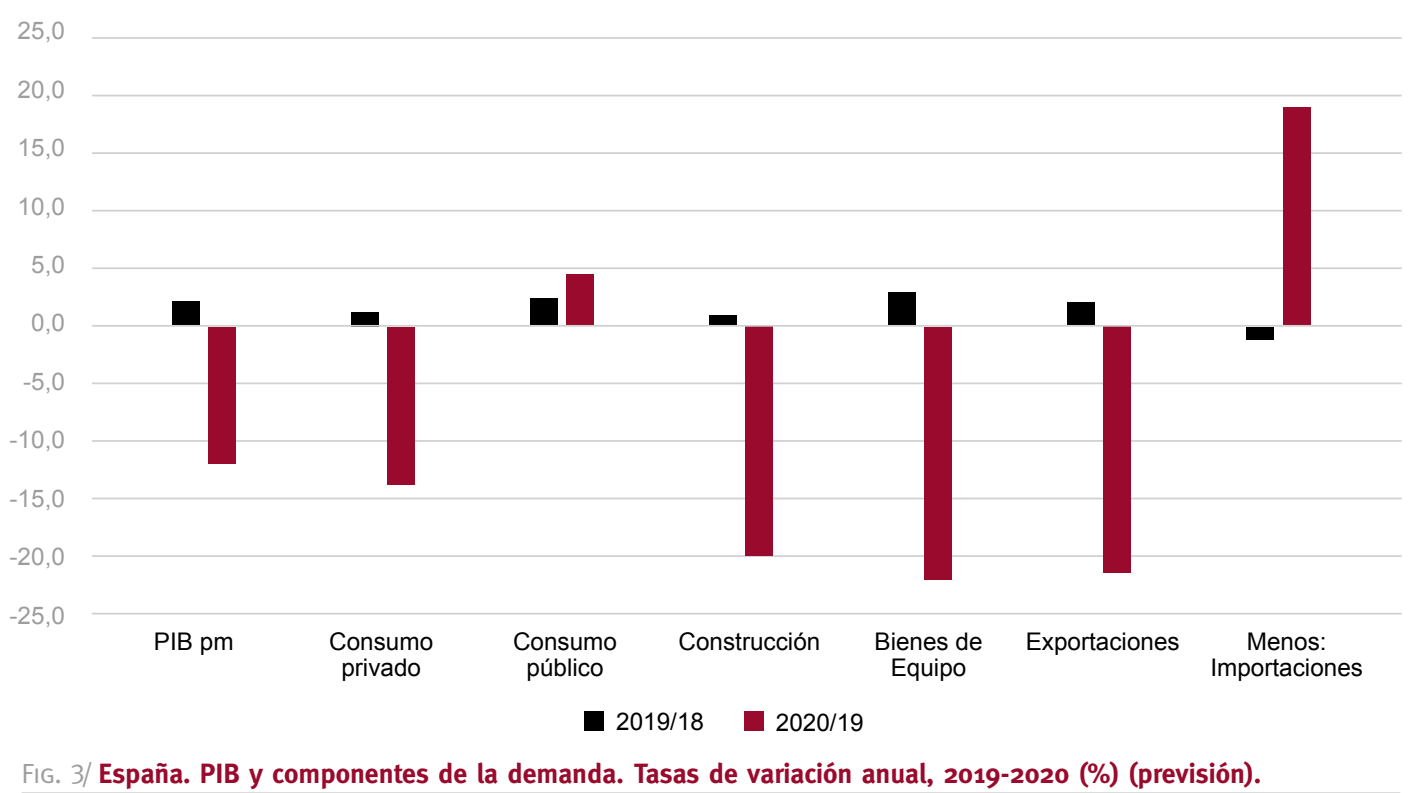

Fuente: INE y FunCAS. 
La intensidad del descenso del PIB en el primer semestre del año ha influido sobre la evolución del empleo. En el segundo trimestre de 2020 el número de ocupados según la Encuesta de Población Activa retrocedió en un 7,5\%, frente al $2,9 \%$ que fue la caída registrada en el conjunto de la Eurozona.

El descenso de las horas trabajadas habría sido el $11,9 \%$ en el segundo trimestre del año según el escenario primero del Banco de España, mientras que en el segundo escenario dicho retroceso alcanzaría al 14,1\%. Según Eurostat, España fue también el país de la Eurozona que registró el mayor descenso en el número de horas trabajadas.

Los descensos del empleo EPA y de los afiliados a la Seguridad Social presentan una menor intensidad por el efecto que desempeñan los ERTEs,que mantienen empleo sin trabajar en las em-presas afectadas (FIG. 4). La tasa media de desempleo en el escenario primero del Banco de España sería el $11,9 \%$ en 2020 , mientras que se elevaría al $14,1 \%$ en el segundo escenario.

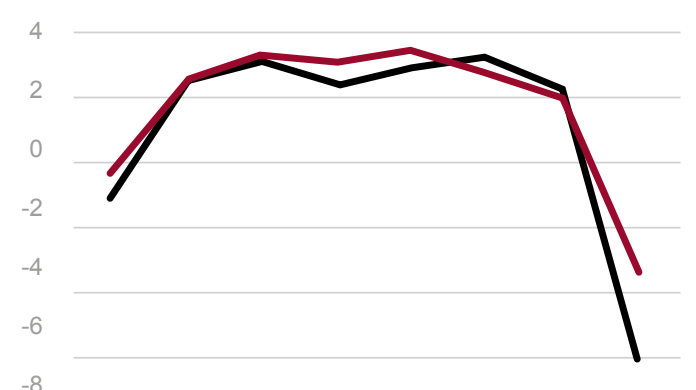

$20132014201520162017201820192020^{*}$

$$
\text { - SS } \longrightarrow \text { Ocup. EPA }
$$

FIG. 4/ Empleo, España. Variaciones anuales del empleo, según la EPA y según la Afiliación a la Seguridad social, 2013-2020 (previsión) (\%). Datos a fin de año.

Fuente: INE y MinISTERIO de TRABAJo.

La pandemia ha afectado seriamente a las cuentas públicas. Por un lado han crecido las prestaciones por desempleo y por los ERTEs y, por otra parte, han descendido las recaudaciones de tributos de forma acusada. De este modo la previsión del consenso de Funcas es de un déficit de las Administraciones Públicas del 12,3\% del PIB en 2020 (FIG. 5). La deuda pública se situaría al final de este ejercicio en el entorno del $118 \%$ $(95,5 \%$ en 2019$)$.

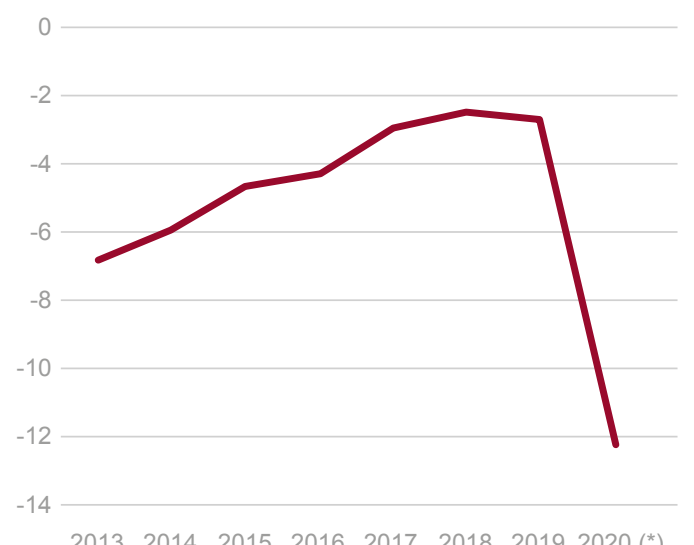

$20132014201520162017201820192020\left(^{*}\right)$

FIG. 5/ Economía española. Saldo de las AA. Públicas, en $\%$ del PIB.

Fuente: Comisión UE y FuncAs.

\section{Mercado de vivienda (I). Los precios}

El índice trimestral de precios de la vivienda del INE se estabilizó en el segundo trimestre del año respecto del trimestre precedente $(0,1 \%)$. Los precios de las viviendas de nueva construcción descendieron en un $-2,2 \%$ y los de las viviendas usadas crecieron en un $0,5 \%$ en el mismo periodo de tiempo. Las variaciones interanuales fueron el $2,1 \%$ para el conjunto de los precios de la vivienda, el $4,2 \%$ para las viviendas nuevas y el 1,6\% para las viviendas usadas (FIG. 6).

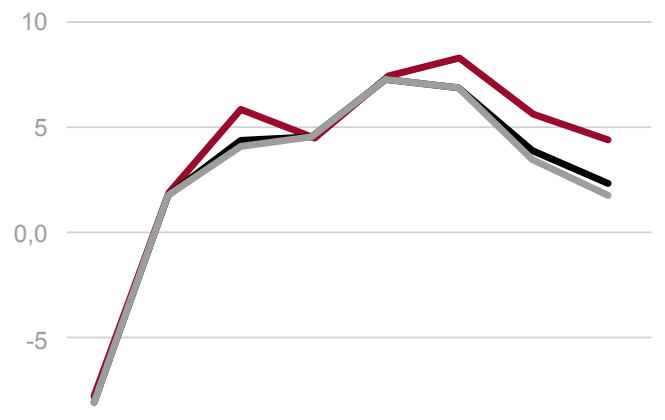

$-10$

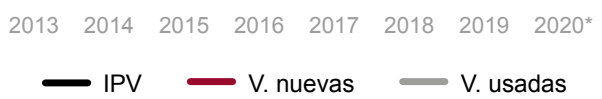

FIG. 6/ Índice de precios de vivienda. Total, nuevas y usadas. Tasas de variación anual, 2013-2020 (previsión) (\%). 
En el periodo citado destacaron los descensos intertrimestrales experimentados en las autonomías de Canarias $(-1,1 \%)$, Madrid y Navarra $(-0,6 \%)$ y Baleares $(-0,5 \%)$. La práctica estabilización de los precios de las viviendas en el segundo trimestre de 2020 coincidió con descensos muy acusados en las ventas de viviendas, tanto nuevas como usadas.

En las autonomías que hasta ahora habían experimentado aumentos de baja intensidad tuvieron lugar aumentos intertrimestrales significativos, como fue el caso de Castilla y León (2,3\%), Extremadura $(1,9 \%)$ y Asturias $(1,7 \%)$. Las variaciones interanuales más acusadas de precios de las viviendas durante el segundo trimestre de 2020 correspondieron a las autonomías de Baleares $(4,6 \%)$ y Asturias (3,8\%). Por el contrario, Navarra $(1,2 \%)$ y Canarias $(0,6 \%)$ presentaron los menores aumentos interanuales (FIG. 7).

Lo más destacable del comportamiento de los precios de las viviendas fue el descenso intertrimestral citado en el caso de las viviendas de nueva construcción, pues no disminuyó el índice general de precios. En cambio, según la estadística de precios publicada por el portal Idealista.com, en el segundo trimestre de 2020 tuvo lugar un descenso del 2,6\% en los precios de las viviendas respecto del trimestre precedente. En los meses de julio y agosto se inició una recuperación de los precios de las viviendas según dicho indicador, siguiendo así una evolución paralela a la de las ventas de viviendas.

En agosto de 2020 los precios de las viviendas, estimados por Idealista.com, descendieron en un $0,8 \%$ sobre el mismo mes de 2019 . Destacaron los aumentos interanuales de País Vasco $(3,3 \%)$ y Andalucía (1,3\%). En agosto de 2020 los precios de las viviendas, analizados por autonomías, según la citada fuente estadística, presentaron los niveles absolutos más elevados en Baleares (3.060 euros $/ \mathrm{m}^{2}$ ), Comunidad de Madrid $\left(2,782\right.$ euros $\left./ \mathrm{m}^{2}\right)$, mientras que los precios menos elevados fueron los de Castilla-La Mancha (848 euros/m²), (FIG. 7 bis).

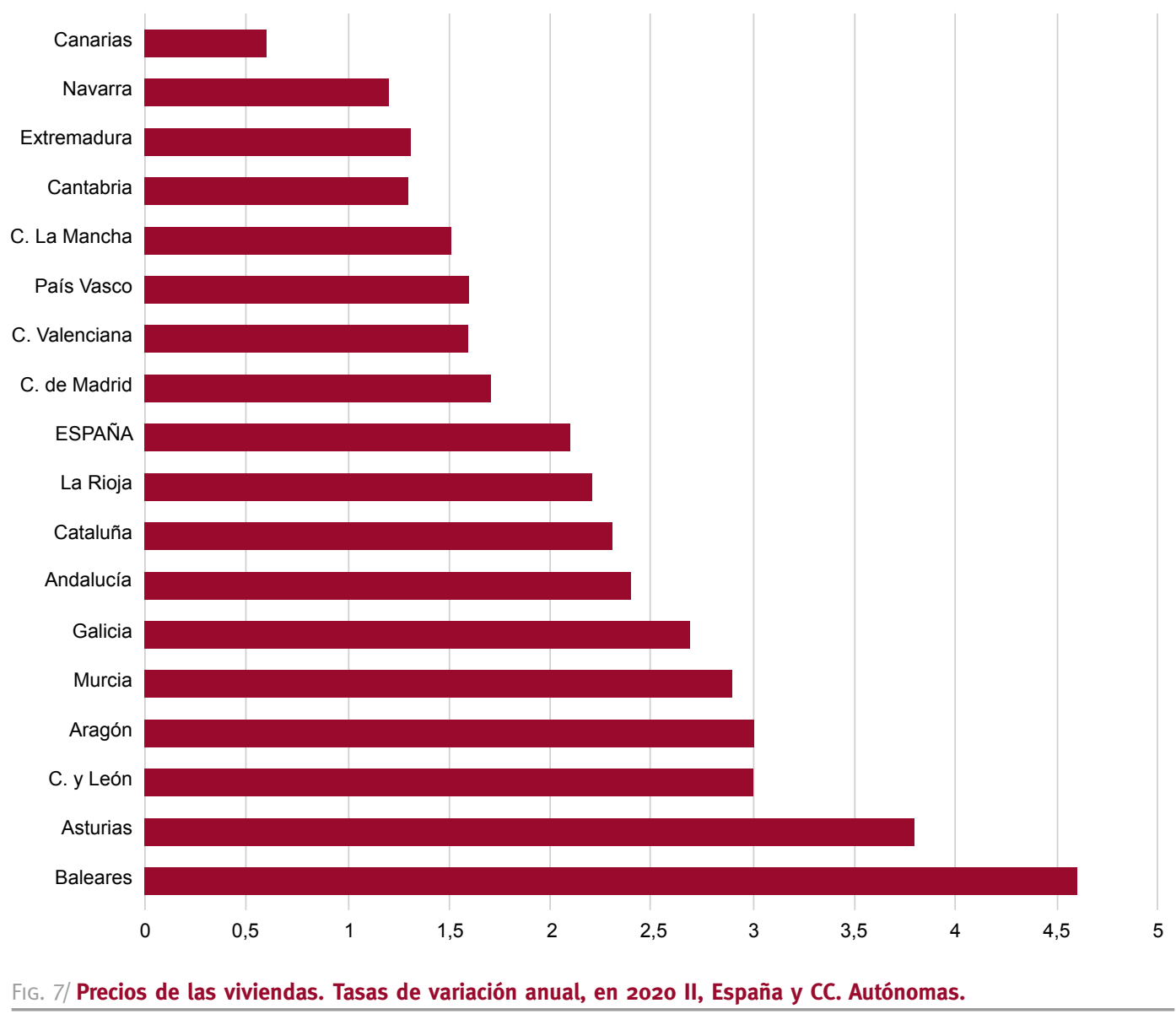

Fuente: INE. 


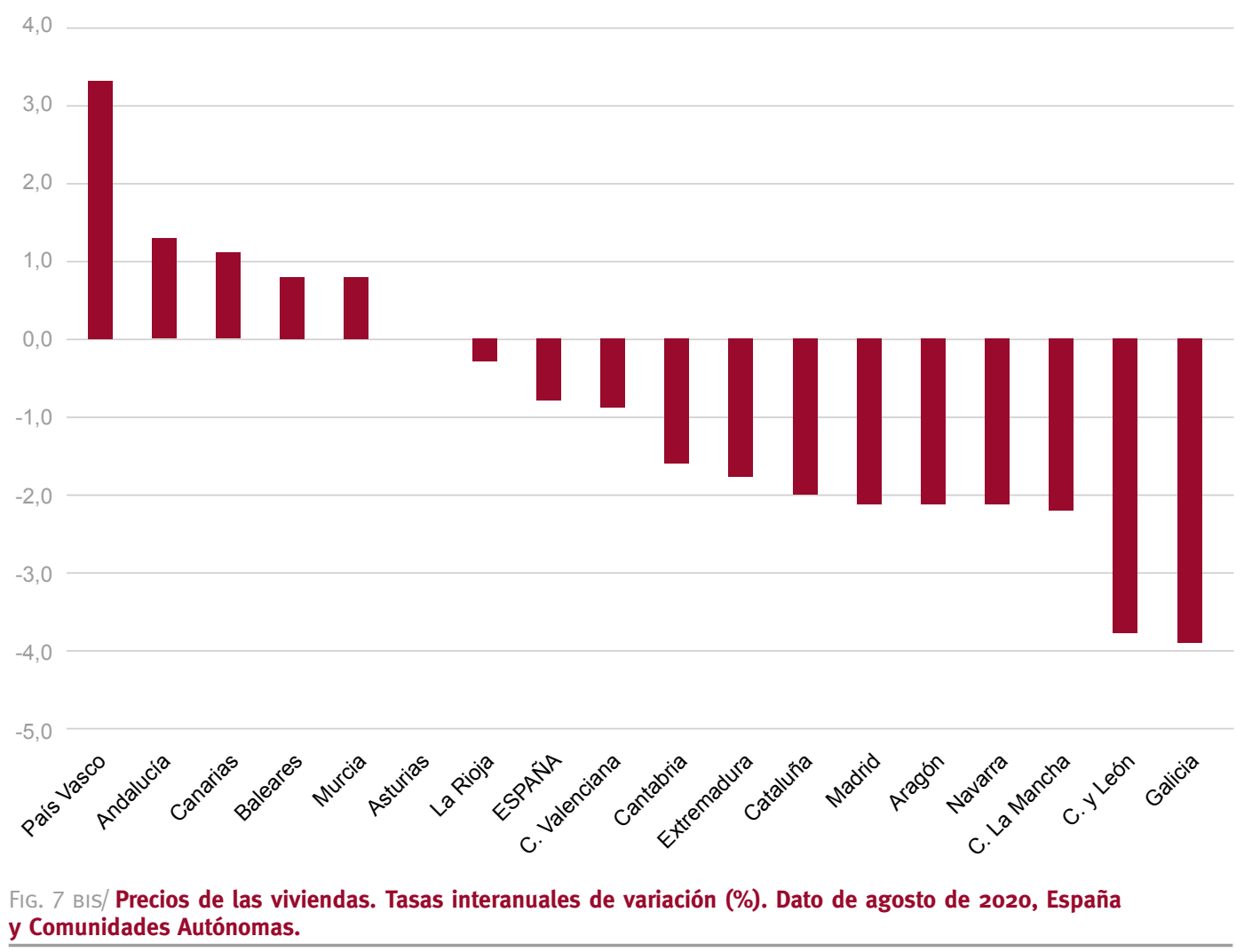

Fuente: Idealista.com.

En cuanto a los alquileres, los datos del portal Idealista.com alcanzaron en junio de 2020 un nivel de 11,4 euros por $\mathrm{m}^{2}$ y mes, que es el mismo nivel que alcanzaban en abril de este año. Se advierte una estabilización de los precios de los alquileres en el segundo trimestre del año y en los meses de julio y de agosto de 2020 , en un periodo en el que los precios de las viviendas estaban descendiendo (FIG. 8).

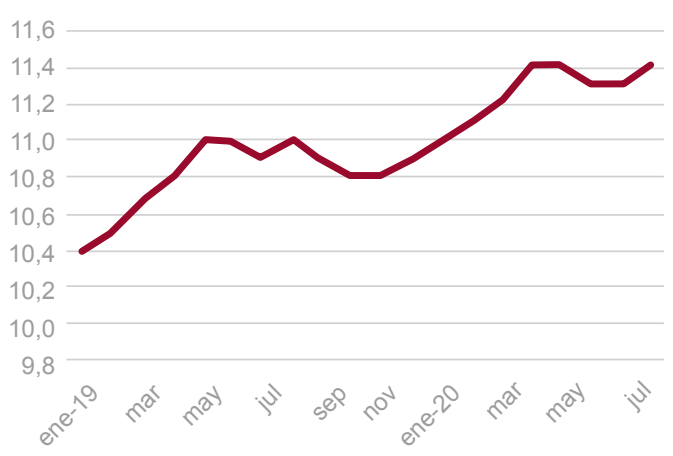

FIG. 8/ Alquileres de viviendas (euros/m²-mes), Datos mensuales, 2019-2020.

Fuente: Idealista.com.
Lo anterior indica que mientras que los precios de las viviendas han descendido, aunque ligeramente, por las menores ventas de viviendas, los precios de los alquileres no han bajado, situándose en agosto de 2020 un $4 \%$ por encima del nivel del mismo mes del año anterior, según los datos del portal Idealista.com.

Los niveles más elevados de los precios de los alquileres en agosto de 2020 correspondieron a la Comunidad de Madrid (15 euros $/ \mathrm{m}^{2}$-mes) y Cataluña $\left(14,6\right.$ euros $/ \mathrm{m}^{2}$-mes). Los precios más reducidos de los alquileres correspondieron a las autonomías de Castila-La Mancha (5,6 euros $/ \mathrm{m}^{2}$-mes) y Extremadura (5,4 euros/ $\mathrm{m}^{2}$-mes) (FIG. 9).

Entre 2013 y 2020 los precios de los alquileres han presentado un aumento acumulado del $57,5 \%$, superior al de los precios de las viviendas $(34,4 \%)$. En ambos casos los precios y, sobre todo, los alquileres, han quedado muy por encima de los salarios, que descendieron en un $5,9 \%$ en el periodo de tiempo citado, reflejando la intensidad del retroceso experimentado en 2020 (-9,4\% fue el descenso interanual registrado en el segundo trimestre del año) (FIG. 10). 


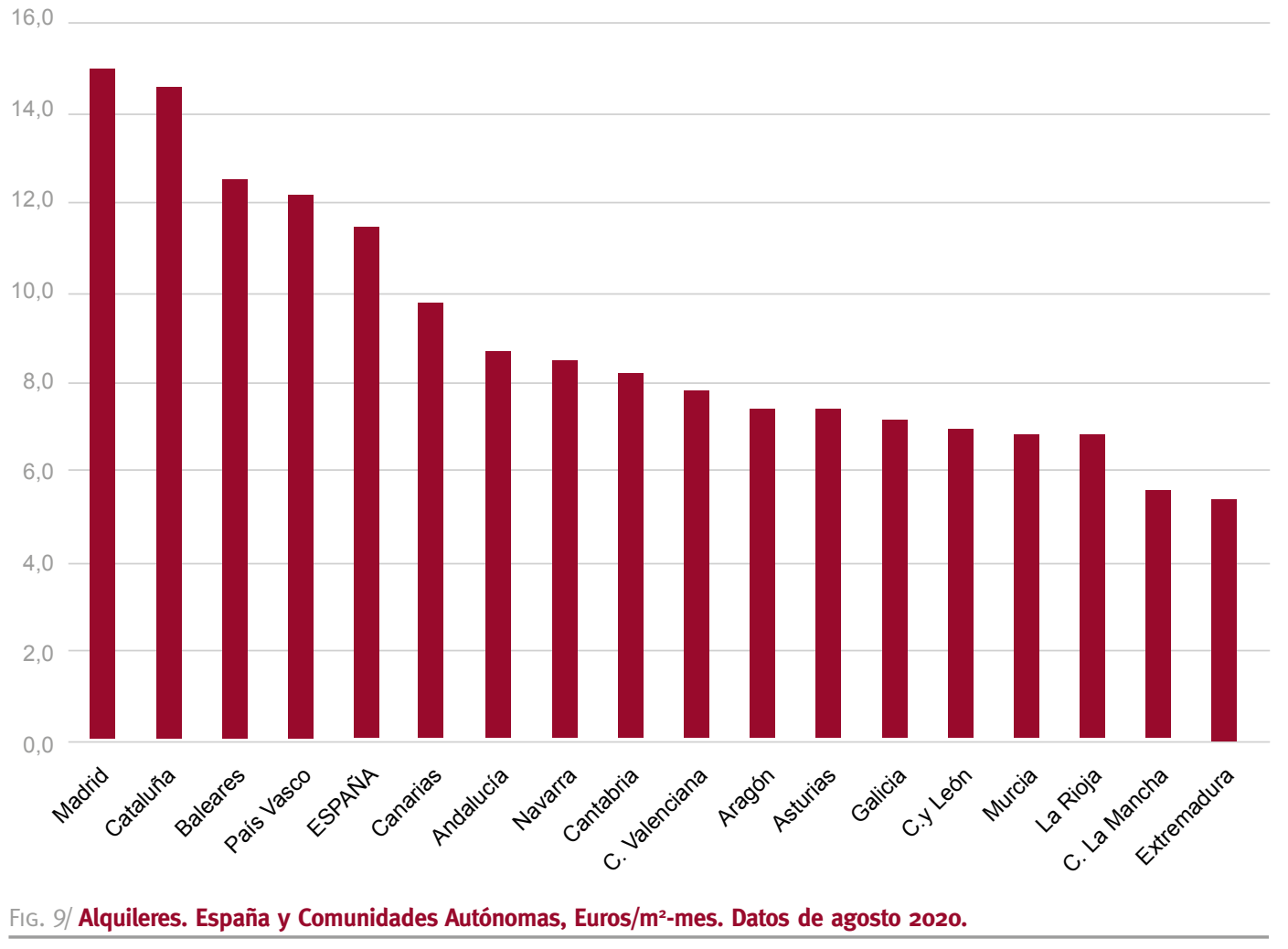

Fuente: Idealista.com.

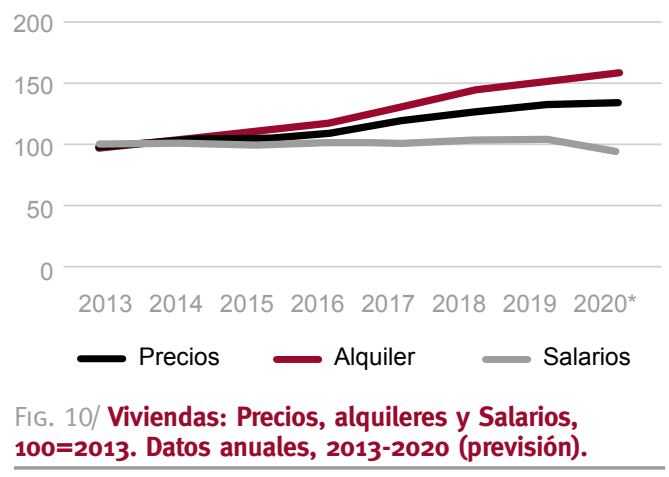

Fuente: INE e Idealista.com.

\section{Mercado de vivienda (II). Demanda de vivienda y financiación}

El confinamiento a que obligó la pandemia afectó de forma negativa al mercado de vivienda. Los datos revelan la presencia de descensos intensos en las ventas de viviendas en el segundo trimestre de 2020, retrocesos moderados en los precios y estabilización y recuperación posterior de los alquileres.
En el segundo trimestre de 2020 los salarios por persona ocupada descendieron en un $4,5 \%$ sobre el trimestre precedente, con lo que la variación anual de dicha magnitud fue de una caída del 9,4\%. Esta evolución, junto al descenso de la actividad y de los empleos sufridos en el mismo periodo, contribuyó a que en dicho trimestre descendiese la renta disponible de los hogares.

La disminución del empleo se reflejó el intenso descenso de la afiliación a la Seguridad Social en marzo y abril de 2020 y en la Encuesta de Población Activa del segundo trimestre. Entre mayo y agosto de 2020 creció el número de afiliados, pero los 18,6 millones de afiliados del último día de agosto están por debajo de los 19,3 millones de afiliados de fines de febrero de este año. El número de afiliados de agosto era inferior en un $3,4 \%$ al número correspondiente al mismo periodo de 2019. (FIG. 11).

El descenso de las hipotecas registradas sobre viviendas confirmó la evolución observada en la demanda. En el primer semestre de 2020 el total de tales préstamos hipotecarios registrados disminuyó en un $8,4 \%$ sobre el año precedente (FIG. 12). 


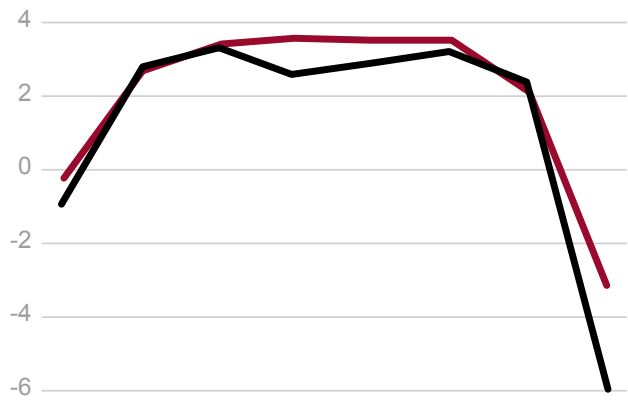

2013201420152016201720182019 2020* - SS - Ocup, EPA

FIG. 11/Empleo, tasas interanuales 2013-2020 (previsión). Datos de la EPA y de la afiliación a la Seguridad Social.

Fuente: MinISTERIO dE Trabajo e INE.

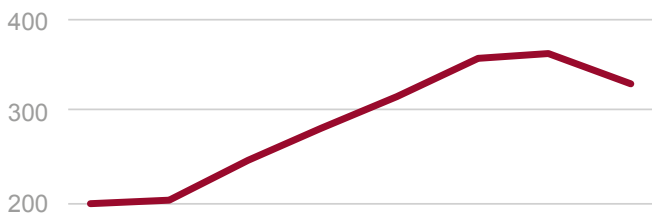

100

0

$20132014201520162017201820192020^{*}$

FIG. 12/ Número de hipotecas sobre viviendas (miles). totales anuales, 2013-2020 (previsión).

Fuente: INE.

Dicho descenso resultó superior al $25 \%$ según la estadística del Consejo General del Notariado, cuyos datos se adelantan a los procedentes de los registros de la propiedad. La mayor proporción de los préstamos hipotecarios sobre las ventas de viviendas implica una menor presencia de los compradores con fines de inversión, que no suelen emplear las hipotecas para la realización de sus adquisiciones. (FIG. 13)

Los tipos de interés de los préstamos a comprador de vivienda retrocedieron entre febrero $(1,816 \%)$ y junio $(1,735 \%)$ (FIG. 14$)$.

El mayor descenso observado en el Euribor a doce meses implicó una elevación de los diferenciales sobre el índice de referencia, que se han situado en torno al $2 \%$.

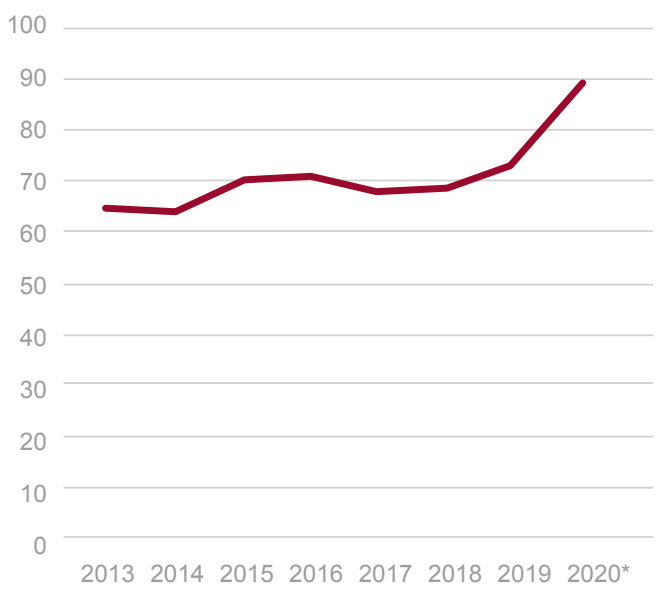

FIG. 13/ Hipotecas para compra de viviendas sobre compraventas registradas, proporción (\%). Medias anuales, 2013-2019.

Fuente: INE.

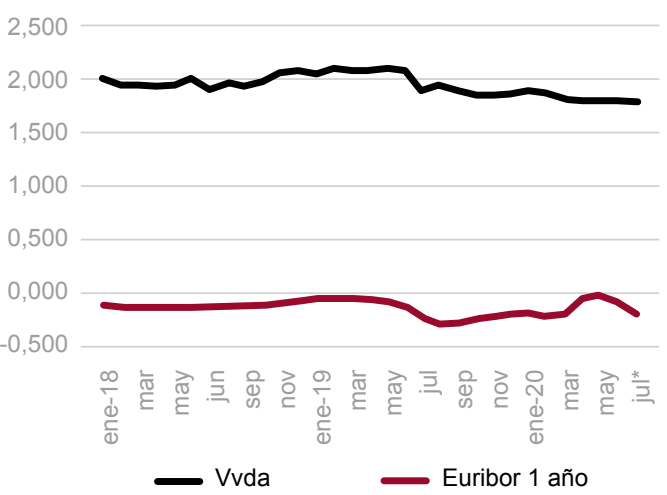

FIG. 14/ Tipos de interés de los préstamos a comprador de vivienda y euribor a 12 meses. Datos mensuales, 2019-2020.

Fuente: BANCO DE EsPaña.

En 2020 ha seguido aumentando el peso de las hipotecas a tipo de interés fijo, que han supuesto el $47,9 \%$ de las hipotecas registradas en el primer semestre $(41,7 \%$ fue la proporción media de 2019). El plazo medio de las hipotecas citadas en dicho periodo ha sido de 23 años.

En cuanto a la evolución de la cuantía de los préstamos a comprador de vivienda, el saldo vivo de dicha magnitud era inferior en julio de 2020 al de diciembre de 2019, presentando en dicho mes de julio un descenso interanual del $1,7 \%$. El flujo de nuevos préstamos formalizados a compradores de viviendas en el periodo enero-julio descendió en un $10,8 \%$ sobre el año precedente, resultando mayor la caída de los prestamos no renegociados (FIG. 15). 


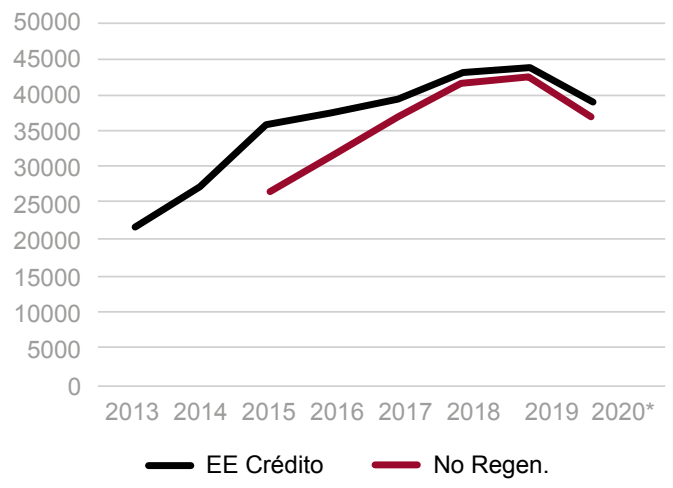

FIG. 15/ Nuevos préstamos formalizados, créditos a comprador de vivienda y operaciones no renegociadas. Datos anuales, 2013-2020 (previsión).

Fuente: BANCO dE EsPaña.

Lo anterior implica que no solo han descendido los nuevos préstamos, sino que han crecido los préstamos renegociados. Esta evolución era previsible, a la vista de las dificultades que para la amortización de préstamos concedidos anteriormente suponía la situación de fuerte descenso de la actividad y del empleo que originó la pandemia y el confinamiento.

El descenso de la renta disponible derivado del descenso del empleo y el retroceso de los salarios afectaron a las compras de viviendas de forma negativa en el primer semestre de 2020 en España, de forma equivalente a lo sucedido en otros países de la Unión Europea. Así, en el periodo de enero-julio de 2020 las ventas de viviendas registradas descendieron en un $25,9 \%$ sobre el mismo periodo del año anterior. El descenso fue mayor en las ventas de viviendas usadas $(-26,4 \%)$ que en las viviendas de nueva construcción (-22,8\%) (FIG. 16).

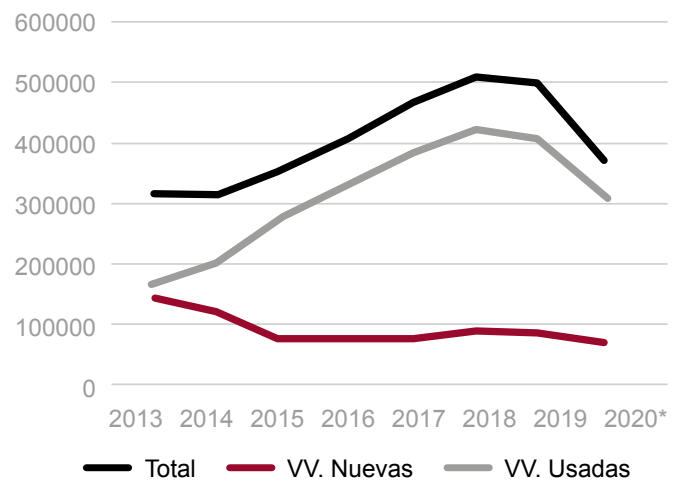

FIG. 16/ Compraventas de viviendas registradas. Totales anuales, nuevas y usadas, 2013-2020 (previsión).

Fuente: INE.
En julio de 2020 el descenso interanual de las compraventas registradas de viviendas fue el $32,4 \%$. Solo registraron un aumento sobre el año anterior las ventas realizadas en el País Vasco $(14,7 \%)$. En el resto de las autonomías se produjeron descensos, destacando el hecho de que la intensidad de la caída fue mayor en Baleares $(-42,9 \%)$ y Canarias $(-54,6 \%)$ que en el resto. La disminución de las ventas fue, pues, mucho más acusada en las autonomías con mayor peso de la actividad turística. También fue notable el descenso en la Comunidad de Madrid y en Cataluña, que habían registrado crecimientos importantes en la etapa de recuperación comprendida entre 2014 y 2019.

El análisis de la serie mensual de compraventas de viviendas registradas revela que hubo importantes descensos de dicha serie en el periodo comprendido entre marzo y mayo de 2020. En los meses de junio y de julio de 2020 se ha producido una clara recuperación de las ventas de viviendas, pero todavía el nivel resulta inferior al de los dos primeros meses de 2020 (FIG. 16 bis).

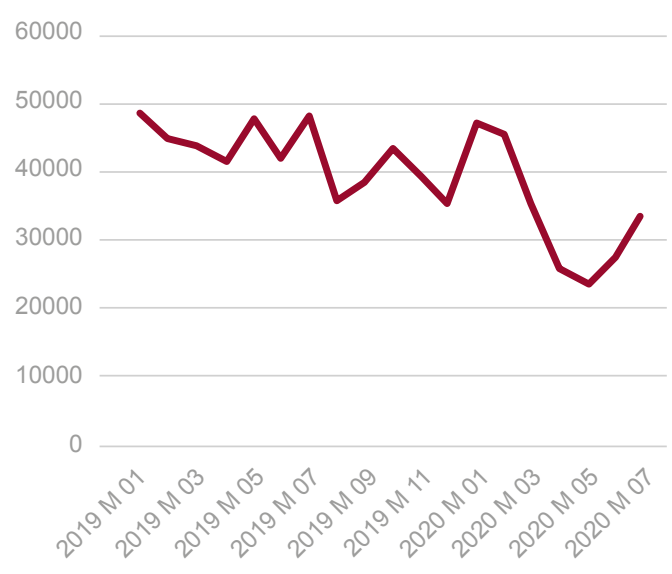

FIG. 16 BIS/ Compraventas registradas de viviendas, -Serie mensual, 2019-2020.

Fuente: INE.

La evolución de las ventas de viviendas según los datos procedentes del Consejo Superior del Notariado, corregidos de estacionalidad, se recuperaron en los meses de mayo y junio de 2020 , tras los intensos descensos sufridos en los meses de marzo y abril (FIG. 17).

La evolución de los diferentes indicadores de la demanda de vivienda apunta a que las ventas de 2020 serán inferiores a las del año anterior. Sin embargo, lo más importante es que se mantenga la intensidad de la recuperación de las 
ventas y del número de préstamos hipotecarios aparecidos en los meses de mayo y de junio. El peor enemigo del mercado de vivienda en España es la posibilidad de nuevos rebrotes de la pandemia, que pueden frenar la intensidad del proceso en marcha de aproximación a los niveles del inicio de 2020.

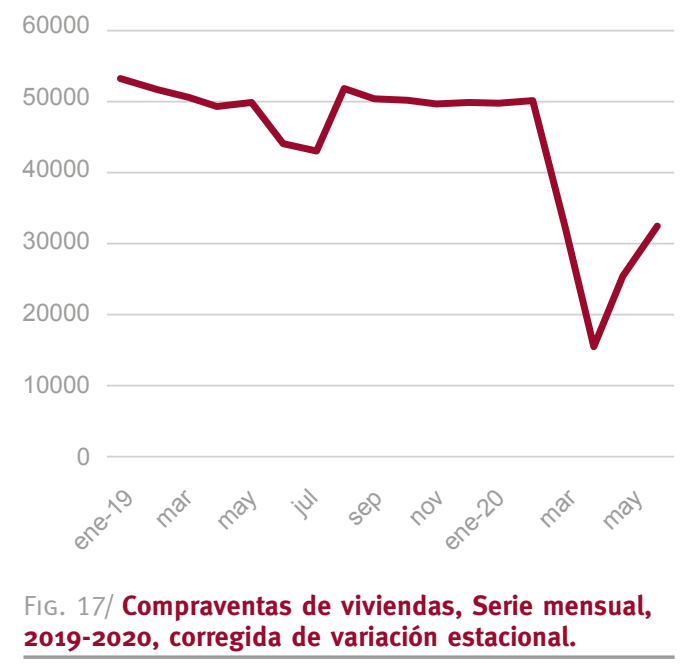

Fuente: Estadistica Registral, Consejo General del Notariado..

\section{Mercado de vivienda (III). La nueva oferta}

El descenso de la demanda de viviendas derivado de la pandemia de coronavirus afectó asimismo a la construcción de nuevas viviendas. Las viviendas iniciadas, medidas por los visados de obra nueva de los Colegios de Arquitectos Técnicos, retrocedieron sobre todo en marzo y abril de 2020. En el periodo enero-mayo de 2020 las viviendas iniciadas descendieron en un $28,7 \%$ sobre el mismo periodo del año precedente, situándose en un nivel de unas 75.000 en 2020. Todo indica que las iniciaciones han debido de recuperarse a partir de los meses de verano, aunque esta evolución también puede resultar afectada por los rebrotes de la pandemia.

Las viviendas terminadas, medidas por los certificados de fin de obra, disminuyeron en un $7,2 \%$ en enero-mayo de 2020 respecto del año precedente (FIG. 18), situándose así en un nivel anual de unas 72.000 viviendas terminadas en 2020. Los visados para obras de rehabilitación disminuyeron en un $30,1 \%$ en los cinco primeros meses del año. La rehabilitación de viviendas supuso el $20,3 \%$ del total de visados en el periodo antes citado.

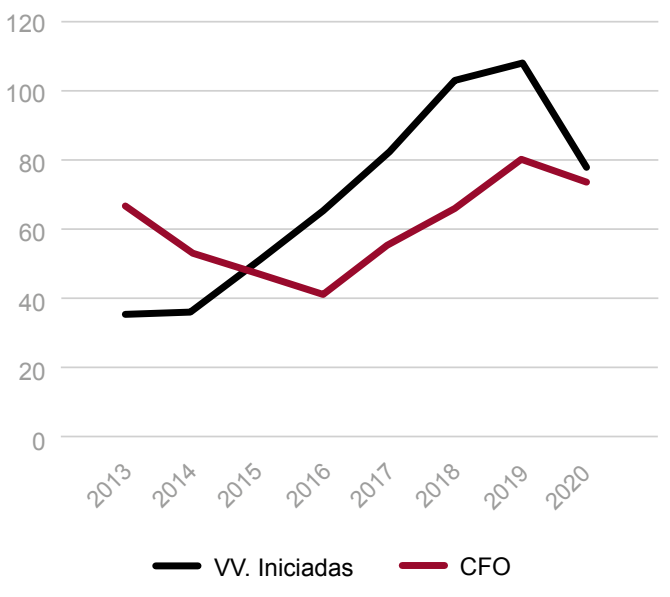

FIG. 18/ Viviendas. Visados de obra nueva y certificados de fin de obra (CFO). Datos anuales, 2013-2020 (previsión).

Fuente: $\mathrm{M}^{\circ}$ de Transportes, Movilidad y Agenda URBana.

En el primer semestre de 2020 el sector de la construcción, estimado por el lado de la demanda, retrocedió en un $20 \%$ sobre el mismo periodo de 2019, según la estimación de la Contabilidad Nacional Trimestral del INE. El descenso interanual de la inversión en vivienda fue similar (-19,9\%). Dicha evolución implicó una caída de la construcción residencial superior a la caída del PIB en el mismo periodo de tiempo $(-13,1 \%)$ (FIG. 19). El retroceso de la construcción residencial detrajo más de un punto porcentual de la variación del PIB en 2020.

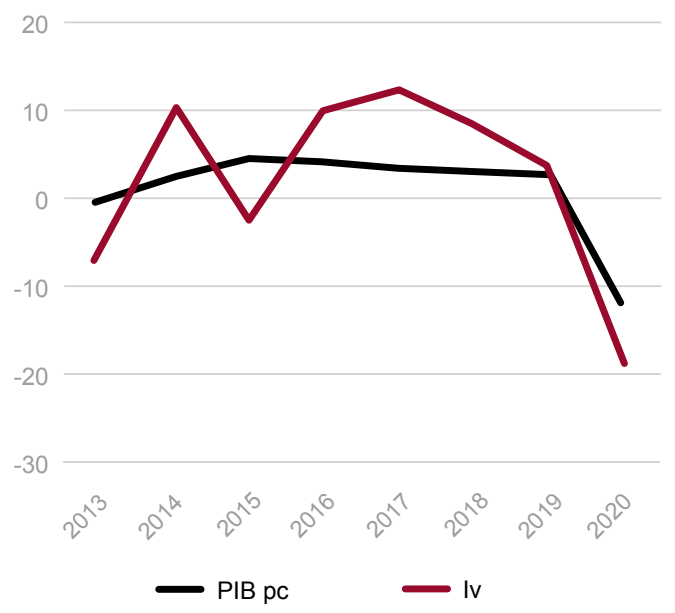

FIG. 19/ Inversión en vivienda y PIB, precios constantes. Tasas de variación anual (\%), 2013-2020 (previsión).

Fuente: INE. 
El Ministerio de Transporte, Movilidad y Agenda Urbana ha estimado el stock de viviendas de nueva construcción no vendidas a fines de 2019 . La cifra estimada es de 457.109 viviendas nuevas no vendidas a 31.12.2019, el 1,77\% del parque de viviendas de España estimado por dicho Ministerio para la misma fecha.

En 2019 el stock citado retrocedió en un 0,41\% respecto del año anterior en España, retroceso sustancialmente menos elevado que el registrado en cada uno de los diez años anteriores. Hubo cinco comunidades autónomas en las que aumentó dicho stock, destacando el aumento de las viviendas no vendidas en la Comunidad de Madrid $(7,8 \%)$ y Cataluña $(3,6 \%)$. El retroceso más acusado fue el del País Vasco (-14,9\%). En las autonomías de Navarra, Cantabria y Extremadura la estimación señala que no hay viviendas nuevas sin vender.

Los niveles más elevados del stock en cuestión eran los de la Comunidad Valenciana (83.577), Cataluña (75.884) y Andalucía (67.585) (FIG. 20). Por provincias fue Madrid la que alcanzó el nivel más elevado (43.283), seguida por Barcelona (41.375).
El Ministerio de Transportes ha realizado asimismo una estimación de la dimensión del parque de viviendas por provincias y autonomías. A 31de diciembre de 2019 el parque total de vivien-das en España ascendió a 25,7 millones de viviendas, un $0,3 \%$ más que en la misma fecha del año anterior. El 25,2\% del total de viviendas citado, casi 6,5 millones de viviendas, correspondió a viviendas no principales (secun-darias y vacías).

La proporción de viviendas no principales ha retrocedido de forma continua en España desde 2011, año en el que se realizó el último Censo de Viviendas, y en el que la proporción de viviendas no principales se elevaba al $28,3 \%$ del total.

Por comunidades autónomas, correspondió a Castilla y León la mayor proporción de viviendas no principales, el $40 \%$ del total, seguida por la Comunidad Valenciana, con el 35,8. La proporción más reducida fue la de la Comunidad de Madrid, con el 9,4\%. La provincia con mayor volumen de viviendas no principales fue Alicante, con 555.853 viviendas de dicho tipo, el $42,6 \%$ del parque de viviendas.

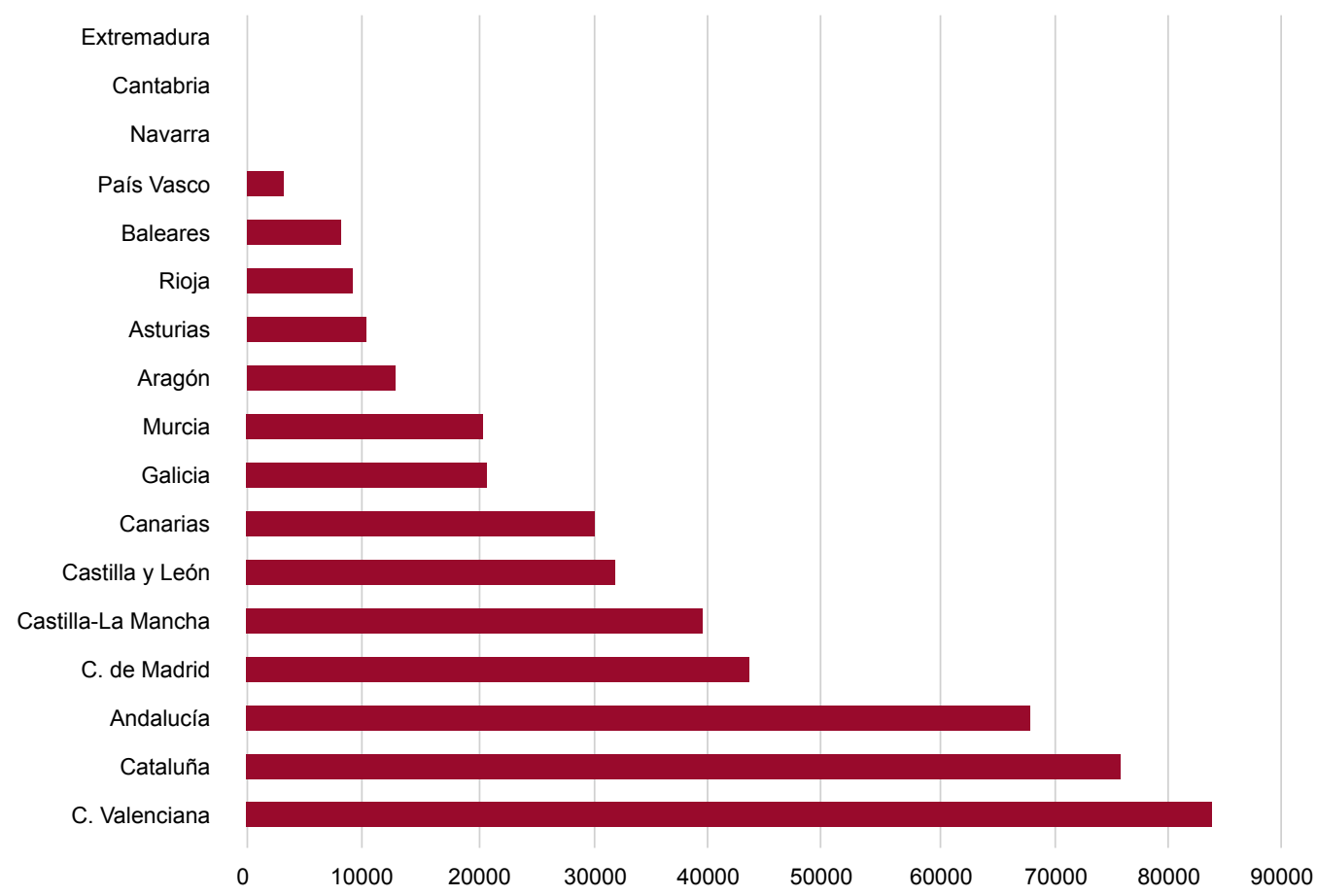

FIG. 20/ Viviendas de nueva construcción no vendidas, datos a 31.12.2019. España y CC.AA. 


\section{Política de vivienda}

Las compraventas registradas de viviendas protegidas, incluyendo las de régimen estatal y autonómico, acusaron el descenso general de ventas y de nueva construcción entre marzo y abril de 2020. A partir de mayo se inició una recuperación que permitió que en el mes de julio las compraventas se aproximaran al nivel de febrero (FIG. 21).

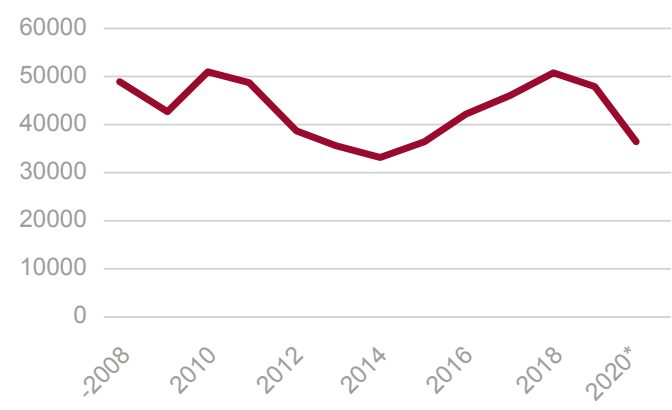

FIG. 21/Compraventas registradas de viviendas de protección oficial (VPO). Totales anuales, 2008-2020 (previsión).

Fuente: INE

El total de las ventas de viviendas protegidas del periodo enero-julio descendió en un $25,1 \%$ sobre el año precedente. El nivel correspondiente a las ventas de los siete primeros meses del año se sitúa por encima de las 35.500 , un 9,6\% del total de ventas de viviendas (FIG. 22).

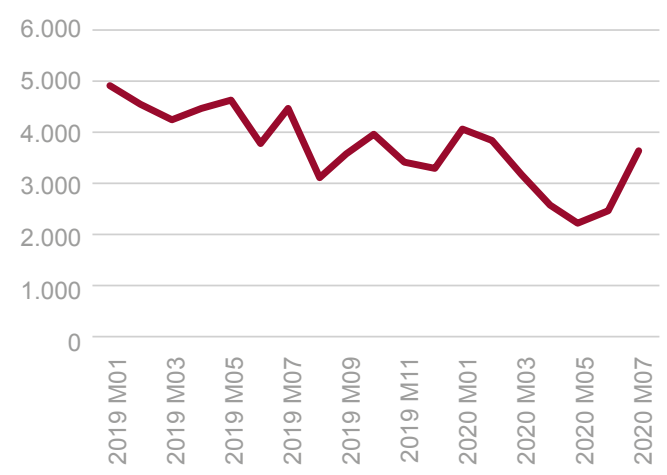

FIG. 22/ Compraventas registradas de viviendas protegidas, España. Datos mensuales, 2018-2019.

Fuente: INE.

En los tres primeros meses de 2020 las calificaciones provisionales de viviendas protegidas disminuyeron en más de un $50 \%$ sobre el año anterior. Dichas calificaciones las otorgan las comunidades autónomas, El descenso interanual de las calificaciones definitivas también fue importante (-45,4\%) (FIG. 23).

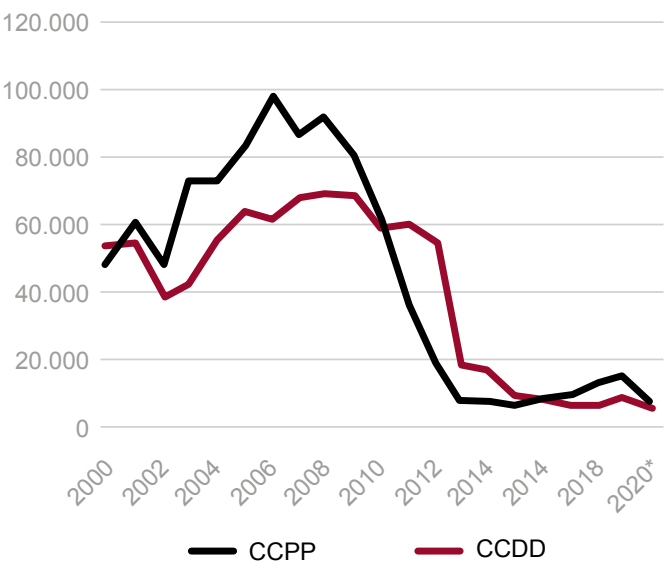

FIG. 23/ Viviendas protegidas, España. Calificaciones provisionales y definitivas. Totales anuales, 2000-2020 (previsión).

Fuente: MINISTERIO DE FOMENTO.

La entrada en el mercado de nuevas viviendas protegidas lleva varios años presentando niveles reducidos (al ritmo de los siete primeros meses las calificaciones provisionales de este tipo de vivienda se situarían en 2020 en torno a las 5.000), muy por debajo del nivel alcanzado por las compraventas. Dentro de estas últimas deben predominar las ventas de viviendas protegidas de segunda mano.

Sin embargo, es necesaria la construcción de viviendas protegidas, sobre todo de las destinadas al alquiler, a la vista de la lejanía entre los precios de venta de las viviendas y de los niveles salariales, que es el rasgo más típico del mercado de vivienda de España.

En cuanto a los lanzamientos judiciales practicados, en el primer trimestre de 2020 hubo un descenso acusado sobre el mismo periodo del año anterior. Los lanzamientos correspondientes a ejecuciones hipotecarias disminuyeron en un $34,1 \%$ sobre el año precedente. El descenso de los lanzamientos asociados con impago de alquileres fue del $33,1 \%$ en el mismo periodo de tiempo.

Al ritmo del primer trimestre de 2020 , en este año los lanzamientos derivados del impago de alquileres ascendería a algo menos de 25.000 , mientras que los relacionados con préstamos hipotecarios morosos estarían por debajo de los 8.000 (FIG. 24).Los lanzamientos previstos para 2020, con datos a los que había afectado poco la pandemia, estarían en total por debajo de los 45.000, muy por debajo de los niveles alcanzados al inicio de la etapa de recuperación de la economía española posterior a la recesión iniciada en 2008 (68.000 en 2014). 


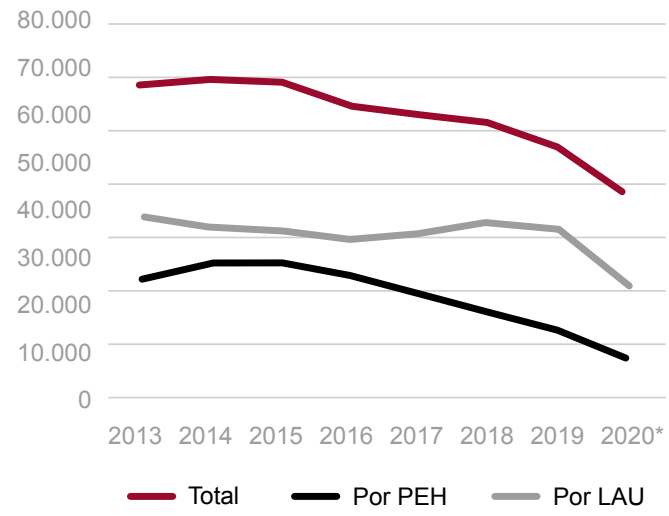

FIG. 24/ Lanzamientos judiciales practicados.

Total, por ejecución hipotecaria y por aplicación LAU. Datos anuales, 2013-2020 (previsión).

Fuente: Consejo General del Poder Judicial.

Las dificultades para hacer frente al pago de los préstamos hipotecarios y a los alquileres como consecuencia de la pandemia del Covid 19 han sido abordadas por el gobierno a través de los Reales Decretos Leyes 8/2020, 11/2020 y $15 / 2020$. La moratoria hipotecaria la introdujo primero el RDL 8/2020, de 17 de marzo y fue especificado y ampliado su ámbito por el posterior RDL 11/2020, de 31 de marzo.

La moratoria hipotecaria citada se aplicaba inicialmente a los préstamos hipotecarios destinados a la compra de vivienda habitual. El segundo de los dos Reales Decretos Leyes antes mencionados extendió la moratoria a los préstamos para la compra de inmuebles afectos a la actividad económica que desarrollen empresas y profesionales, así como para la compra de viviendas secundarias (L. BRAQUEHAIS \& A. ROYOVILLANOVA, 2020).

La norma exige que el deudor sea económicamente vulnerable y la solicitud podía hacerse hasta 45 días después del fin del estado de alarma, acompañada de una documentación que se especifica en otro artículo de esta última norma. Dicha documentación puede incluir una declaración responsable previa a la presentación del documento específico preciso.

El segundo de los tres RDLs citados aclara que la moratoria hipotecaria no la concede el prestamista, sino que es automática, de cumplirse los requisitos legales. Entre sus efectos destacan su duración, que sería de tres meses durante los cuales se suspenden los pagos y no se devengan intereses. Se alargó el periodo de devolución legal también en tres meses, manteniéndose el rango de la hipoteca.
Se prevé la formalización de las novaciones. No se considerarán vencidos los importes exigibles al deudor de no aplicarse la moratoria, lo que significa que el banco no deberá efectuar provisiones por la refinanciación. EI RDL 11/2020 añadió la moratoria para préstamos o créditos sin garantía hipotecaria a personas físicas, y el RDL 19/2020 ha establecido que la moratoria puede afectar a los contratos de arrendamiento financiero o leasing. Los requisitos de vulnerabilidad del deudor son equivalentes a los de la moratoria hipotecaria. La solicitud ha podido realizarse en este caso hasta un mes después del fin del estado de alarma.

El RDL 11/2020 atendió al posible desalojo de los hogares vulnerables sin alternativa habitacional" que viven de alquiler, permitiendo la suspensión extraordinaria del lanzamiento. Los hogares afectados deberían de encontrarse en situación de vulnerabilidad derivada de la pandemia de Covid 19: parados, integrados en ERTEs, autónomos con ingresos inferiores a 3 IPREM.

En caso de pequeño arrendador, los hogares vulnerables podrán solicitar ayudas transitorias de financiación de hasta seis mensualidades de renta, ayudas que concederían los bancos con aval del ICO, pudiendo prorrogarse el contrato. $\mathrm{Si}$ el arrendador es una empresa o gran tenedor de viviendas, el inquilino dispondría de un mes para solicitar el aplazamiento temporal de la renta. El arrendador, transcurrido un plazo de siete días tras la petición, podría optar entre reducir en un $50 \%$ la renta en tanto durase el estado de alarma o establecer una moratoria no superior a cuatro meses de renta.

El inquilino también podría acceder al programa de ayudas transitorias de financiación, esto es, créditos bancarios avalados por el ICO a seis años de plazo que cubriesen hasta seis mensualidades. Se podrían prorrogar los contratos de arrendamiento de vivienda habitual, previa solicitud del arrendatario.

De un plazo de un mes inicial se extendió hasta el 30 de septiembre la posibilidad de solicitar la moratoria o la condonación parcial de la renta (RDL 26/2020, de 7 de julio) en el caso de que el arrendador fuese una empresa o un gran tenedor. Para el caso de un arrendador no gran tenedor el plazo máximo del arrendatario para solicitar la moratoria o condonación parcial de la deuda se extendió hasta el 2 de julio (RDL 16/2020, de 28 de abril).

El plazo máximo para la solicitud de prórroga extraordinaria de seis meses en el vencimiento del contrato se extendió hasta el 30 de septiembre 
(RDL 25/2020, de 7 de julio). La suspensión del desahucio por falta de pago finalizaría el 2 de octubre de 2020 (RDL 11/2020, de 31 de marzo, articulo 1).

\section{Referencias}

Banco de España, (2020): Escenarios Macroeconómicos para la economía española (2020.2022).

Braquehais Conesa, L. \& Álvarez Royo-Villanova, S. (2020): "Las moratorias legales y convencionales de préstamos tras el Covid. Recapitulación tras cuatro Reales Decretos-Leyes (8/2020, 11/2020, 15/2020 y 19/2020)". El Notario del Siglo XXI, Mayo/Agosto.

Comisión EuropeA, (2020): "European Economic Forecast”. Summer 2020

Politi, J. \& SMITH, C., (2020): "Fed signal rock bottom rates until at least end of 2023". Financial Times 16 de septiembre.

REINHART, C. \& REINHART, V., (2020): "The pandemic depression. The global economy will never be the same". Foreign Affairs, Julio/Agosto. 